\title{
Synthesis and Physical Properties of Estolide Ester Using Saturated Fatty Acid and Ricinoleic Acid
}

\author{
Jumat Salimon, Neeranjini Nallathamby, Nadia Salih, and Bashar Mudhaffar Abdullah \\ School of Chemical Sciences and Food Technology, Faculty of Science and Technology, Universiti Kebangsaan Malaysia, \\ 43600 Bangi, Malaysia \\ Correspondence should be addressed to Jumat Salimon, jumat@ukm.my \\ Received 7 July 2011; Revised 6 September 2011; Accepted 18 September 2011 \\ Academic Editor: Eduardo Dellacassa \\ Copyright (C) 2011 Jumat Salimon et al. This is an open access article distributed under the Creative Commons Attribution License, \\ which permits unrestricted use, distribution, and reproduction in any medium, provided the original work is properly cited. \\ A study was conveyed to produce estolide ester using ricinoleic acid as the backbone. The ricinoleic acid reacted with saturated \\ fatty acid from C8-C18. These reactions were conducted under vacuum at $60^{\circ} \mathrm{C}$ for $24 \mathrm{~h}$ without solvent. The reaction used acid \\ catalyst, sulphuric acid. The new saturate ricinoleic estolide esters show superior low-temperature properties $\left(-52 \pm 0.08^{\circ} \mathrm{C}\right)$ and \\ high flash point $\left(>300^{\circ} \mathrm{C}\right)$. The yield of the neat estolide esters ranged from $52 \%$ to $96 \%$. The viscosity range was $51 \pm 0.08$ to $86 \pm$ \\ $0.01 \mathrm{cp}$. These new saturated estolide esters were also compared with saturated branched estolide esters.
}

\section{Introduction}

Castor bean oil contains ricinoleic acid, a hydroxy monounsaturated fatty acid as main constituent of its fatty acid profile. Ricinoleic acid, cis-12-hydroxy-9-octadecenoic acid, has an unusual polarity due to position of hydroxyl group [1]. Castor oil is the only commercially available vegetable oil containing hydroxy functionality of a fatty acid present abundantly (70-90\%) [2].

Ricinoleic acid can undergo a wide range of reactions enabling formation of several derivatives. Its various derivatives like ricinoleyl alcohol, methyl ricinoleate, azelaic acid, and ricinenic acid are used as plasticizer and emulsifier [3]. Ricinoleic acid derivatives are used in pigment, printing ink, and textile finishing. However, its main use is as chemical intermediate to produce various oleochemicals. Estolides and estolide esters from castor oil, or any source of hydroxy fatty acids [4], have been explored and show promise as cosmetics, coatings, and biodegradable lubricants. Estolides are formed when the carboxylic acid functionality of one fatty acid links to the site of unsaturation of another fatty acid to form oligomeric esters.

Complex estolides have been synthesized by [5] where oleic acid and various saturated fatty acids, butyric through stearic, were treated with 0.4 equivalents of perchloric acid at either 45 or $55^{\circ} \mathrm{C}$ to produce a new class of saturated estolides with superior low-temperature properties. However, no journal has reported using ricinoleic acid as a starting fatty acid. The current work involves the synthesis of a new series of estolide ester from ricinoleic acid and various fatty acids. The effect of fatty acid carbon chain length on physical characterization of these estolide esters was determined.

\section{Materials and Methods}

\subsection{Materials}

Castor beans from experimental plot UKM were used to extract castor oil. Concentrated sulphuric acid (98\%) and potassium hydroxide $(\mathrm{KOH})$ were purchased from J. T. Baker Inc. Caprylic acid (98\%), capric acid (98\%), lauric acid (98\%), myristic acid (99\%), palmitic acid (98\%), stearic acid (96\%), 2-hexyldecanoic acid (96\%), and 2-butyloctanoic acid $(96 \%)$ were purchased from Sigma Aldrich. Ethanol (95\%) and hydrated sodium sulphate (99\%) were purchased from Systerm.

2.2. Experimental Procedure. Estolide ester was synthesized in a one-step reaction in a $250 \mathrm{~mL}$ three-neck round bottom flask with a magnetic stirrer. Concentrated sulphuric acid 
was used as catalyst. The heating mantel was used to maintain the temperature of reaction constant at $60^{\circ} \mathrm{C} \pm 3^{\circ} \mathrm{C}$. Ricinoleic acid $(50 \mathrm{~g}, 0.1678 \mathrm{~mol})$ and branched fatty acid $(0.0839 \mathrm{~mol})$ were combined and heated to $60^{\circ} \mathrm{C}$ temperature. Once the temperature reached $60^{\circ} \mathrm{C}$, acid catalyst $(5 \%)$ was added into reaction and the flask was placed under vacuum and stirred for $24 \mathrm{~h}$. After 24 hours, ethanol $(34 \mathrm{~mL}$, $0.7391 \mathrm{~mol}$ ) was added into the flask and reaction was continued for additional 2 hours in vacuum. As the reaction completed, it was neutralized with $\mathrm{KOH}(10 \mathrm{~mL}, 2 \mathrm{~mol})$ in $90 \%$ ethanol. The round bottom flask was disconnected from the heating mantel and the solution was left to cool down to room temperature. The material was filtered through a Buckner funnel using Whatman 2 filter paper. The organic layer was transferred to a separation funnel and was washed with distilled water to remove any excess ethanol used to neutralize. The organic layer was then distilled using the simple distillation method at $80-140^{\circ} \mathrm{C}$ to remove any lactone, byproducts, excess ethanol and water.

2.3. Physical Properties. Physical properties of the estolide ester were determined. These analyses were FTIR, viscosity, flash point and pour point.

(a) Fourier Transform Infrared Spectroscopy . Fourier transform infrared spectroscopy (FTIR) has been carried out according to [6]. FTIR of the products was recorded by Prkin Elmer Spectrum GX spectrophotometer in the range 400$4000 \mathrm{~cm}^{-1}$. A very thin film of products covered the $\mathrm{NaCl}$ cells ( $25 \mathrm{~mm}$ i.d $\times 4 \mathrm{~mm}$ thickness $)$ and was used for analysis.

(b) Viscosity. Viscosity test, ASTM D445-04 $€_{2}$ [7], was done in a Brookfield viscometer using a number 3 spindle. The speed was set to $100 \mathrm{rpm}$ a minute and was done in room temperature. Triplicate measurements were made, and the average values were reported.

(c) Pour Point. The pour point test, ASTM D97-05a, was done by using a U-tube. The sample was poured into the tube to $3 \mathrm{~cm}$ height. The sample in the tube was kept to freeze in a $-80^{\circ} \mathrm{C}$ refrigerator [8]. Temperature was recorded when the sample started moving after removed from the refrigerator. Triplicate measurements were made, and the average values were reported.

(d) Flash Point. The flash point test, ASTM D92-05a, was conducted by adding $5 \mathrm{~mL}$ sample into a small ceramic bowl. The sample in the small container was partially emerged into a glass bowl of silicon oil and was heated on the heating mantel. A $300^{\circ} \mathrm{C}$ thermometer was dipped in the silicon oil. The heating process will produce gas clouds which were trapped in the ceramic bowl. Starting from $100^{\circ} \mathrm{C}$, fire spark was given to the sample. If there is no spark, the process will be repeated until there is spark [9]. The temperature was stated as the flash point. Triplicate measurements were made and the average values were reported.

\section{Results and Discussion}

A series of estolide ethyl esters were synthesized from ricinoleic acid and a series of saturated fatty acids with sulphuric acid catalyst at $60^{\circ} \mathrm{C}$ for $24 \mathrm{~h}$. The structures are shown in Figure 1. Esterification process was continued with synthesis of estolide ester by adding an alcohol, ethanol to stop the estolide chain by capping it. The estolide esters were formed under vacuum distillation at $60^{\circ} \mathrm{C}$ for 2 hours. The temperature of the process should be kept stable and not exceed $70^{\circ} \mathrm{C}$ because the productions of byproducts such as lactone [10] will increase and decrease the temperature to less than $45^{\circ} \mathrm{C}$ because of the slower rate of estolide formation [10]. A base was added to neutralize the acidic product, $\mathrm{pH} 7$.

FTIR spectra of ricinoleic acid and reaction products were compared to show that condensation had occurred. As a result, the FTIR spectrum of ricinoleic acid shows $\mathrm{C}=\mathrm{O}$ stretching band at $1713 \mathrm{~cm}^{-1}$ wavenumber and the presence of a hydroxyl group in the ricinoleic acid structure is shown $3445 \mathrm{~cm}^{-1}$ wavenumber where else the reaction product, a sharp and long carbonyl $\mathrm{C}=\mathrm{O}$ ester transmittance peak was observed at $1737 \mathrm{~cm}^{-1}$. The presence of $\mathrm{CH}_{2}$ bending at $723 \mathrm{~cm}^{-1}$ wavenumber indicates long-chain compound. The, $\mathrm{C}=\mathrm{C}$ transmittance peak are pot clearly presence because it, showed a weak transmittance peak due to only a small amount of alkene was present. From the observation, no lactones were present because of there is no transmittance peak at $1790 \mathrm{~cm}^{-1}$ [11]. Other absorbance indicates $\mathrm{C}-\mathrm{H}$ alkane bond and bend alkane at transmittance peaks $2926 \mathrm{~cm}^{-1}$, $2854 \mathrm{~cm}^{-1}$ and $1464 \mathrm{~cm}^{-1}$, respectively.

The physical characterisation of the estolide ethyl ester is shown in Table 1. The yield of these estolides increased from $52.51 \pm 0.03 \%$ to $96.57 \pm 0.05 \%$ for the neat and capped estolide esters. The highest yield was $96.57 \pm 0.05 \%$ obtained with sample EE14. This estolide was synthesized using ricinoleic acid with myristic acid (C14). The lowest yield was obtained with sample EE10, $52.51 \pm 0.03 \%$. This estolide was synthesized with ricinoleic acid and capric acid.

The pour point of saturated estolide ethyl esters is shown in Table 1. Pour point is the lowest point or temperature where the sample sustains in liquid form [12]. This property is important because low pour point enables the sample usage in cold countries and in low-temperature machineries. Low pour point helps in keeping the estolides in liquid condition which makes transportation and storage easy. The lowest pour point is obtained from EE8 which is $-52 \pm$ $0.08^{\circ} \mathrm{C}$. Shorter fatty acid gives a better and lower pour point. It is because the longer estolide esters have bigger molecular structure and bulky which makes them easier to solidify at a higher temperature compared to small compounds. The highest pour point is EE18 with $-10 \pm 0.04^{\circ} \mathrm{C}$. Even though the pour point pattern is increasing, the values of pour point are still negative and are low.

Viscosity is a measure internal friction taking place in fluid. It also determines fluid properties involved in lubricant, resistant to the initiation of relative movement of moving part [13]. The highest viscosity is obtained at $86 \pm 0.01 \mathrm{cp}$ for EE18 and the lowest at $51 \pm 0.08 \mathrm{cp}$ for EE16. The range of viscosity of these estolide ethyl esters is relatively 


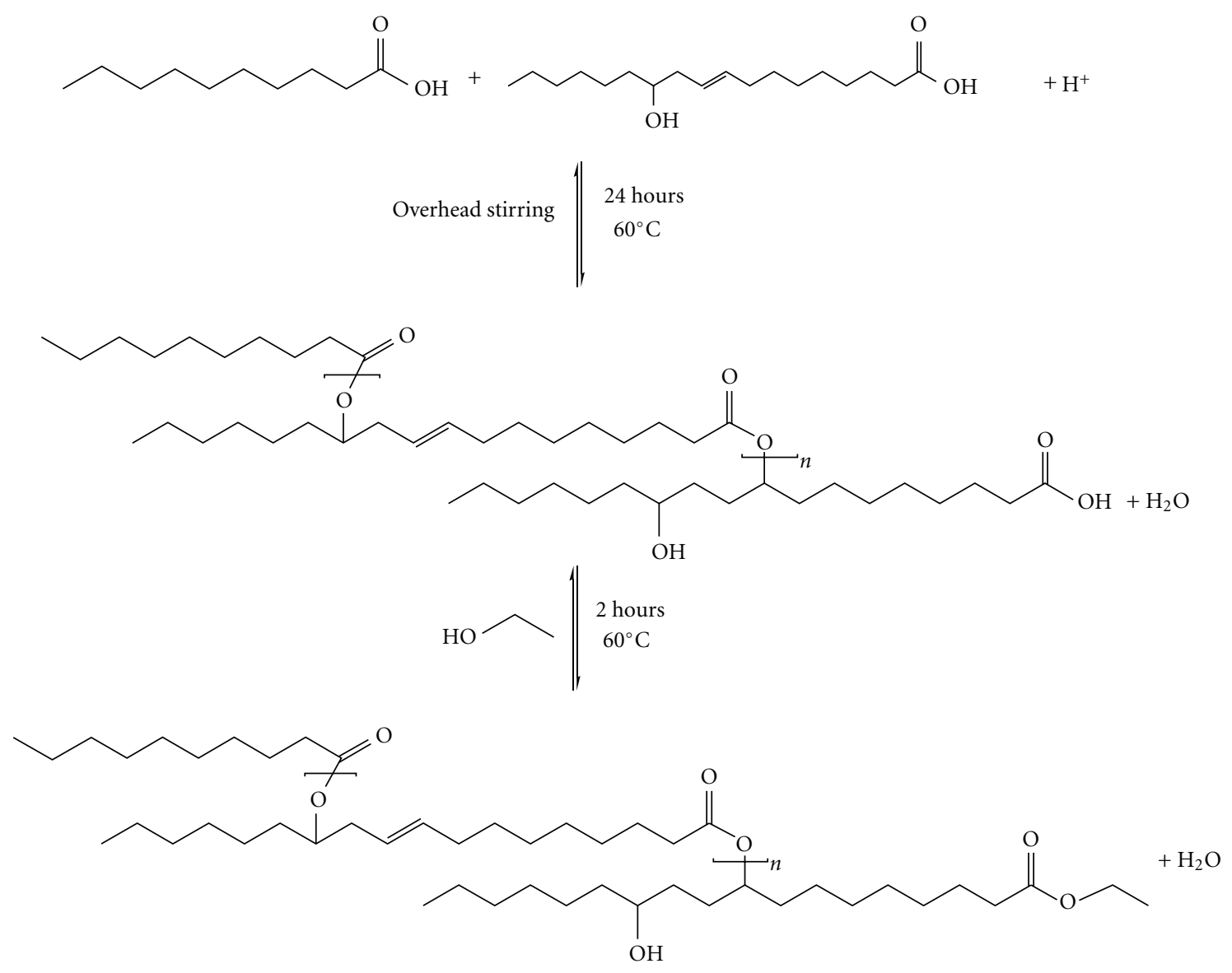

FIgURE 1: Reaction of estolide ester formation between ricinoleic acid and decanoic acid.

TABle 1: Physical characteristics of ricinoleic acid estolide ester.

\begin{tabular}{|c|c|c|c|c|c|}
\hline Sample & Fatty acid & Viscosity (cp) & Flash point $\left({ }^{\circ} \mathrm{C}\right)$ & Pour point $\left({ }^{\circ} \mathrm{C}\right)$ & Yield (\%) \\
\hline EE08 & Caprylic & $76 \pm 0.03$ & $>300$ & $-52 \pm 0.08$ & $91.43 \pm 0.07$ \\
\hline EE10 & Capric & $84 \pm 0.10$ & $>300$ & $-48 \pm 0.01$ & $52.51 \pm 0.03$ \\
\hline EE12 & Lauric & $81 \pm 0.05$ & $>300$ & $-42 \pm 0.03$ & $74.65 \pm 0.10$ \\
\hline EE14 & Myristic & $56 \pm 0.02$ & $>300$ & $-38 \pm 0.09$ & $96.57 \pm 0.05$ \\
\hline EE16 & Palmitic & $51 \pm 0.08$ & $>300$ & $-12 \pm 0.02$ & $84.15 \pm 0.08$ \\
\hline EE18 & Stearic & $86 \pm 0.01$ & $>300$ & $-10 \pm 0.04$ & $84.03 \pm 0.06$ \\
\hline
\end{tabular}

average. They have been proven to be useful for numerous applications. The value of viscosity reduces as the length of fatty acid increases [14].

The flash point, or the temperature at which a lubricant momentarily flashes in the pressure of a test flame, aids in evaluating fire-resistance properties [9]. It also shows that there is a possibility that there are hazardous gasses in the sample. It is important to have a high flash point to ensure it will not harm the user or the environment by releasing gas emission at low-temperature. The flash point temperature should also be high to ensure its usage is commercially accepted. The flash points for all the samples were above $300^{\circ} \mathrm{C}$. They are high and are not easily to emit any dangerous gaseous or potential fire occurrence during usage of the estolides.
These new estolide esters were compared with saturated branched-chain estolide esters. EE12 and EE16 were compared with EEBO and EEHD, respectively. The saturated branched estolide esters were synthesized the same way as the above esters. The comparisons were made according to similar molecular weight and number of carbon. The comparison of physical characterisations between these estolide ethyl esters is shown in Table 2. Overall the saturated branchedchain estolide esters show better physical characterisation. EEBO and EEHD have lower pour point and higher viscosity.

Saturated branched-chain estolide ester has lower pour point and viscosity especially if EE16-compared to EEHD. The difference is more than double. This may be caused by the addition of branched fatty acid that causes the structure 
TABLE 2: Comparison between straight-chain saturated fatty acids and branched-chain saturated fatty acids.

\begin{tabular}{|c|c|c|c|c|c|}
\hline Sample & Fatty acid & Viscosity (cp) & Flash point $\left({ }^{\circ} \mathrm{C}\right)$ & Pour point $\left({ }^{\circ} \mathrm{C}\right)$ & Yield (\%) \\
\hline EE12 & Lauric & $97 \pm 0.10$ & $>300$ & $-42 \pm 0.04$ & $74.7 \pm 0.07$ \\
\hline EEBO & 2-Butyloctanoic & $242 \pm 0.07$ & $260 \pm 0.09$ & $-43 \pm 0.02$ & $77.9 \pm 0.05$ \\
\hline EE16 & Palmitic & $63 \pm 0.03$ & $230 \pm 0.04$ & $-12 \pm 0.10$ & $84.2 \pm 0.02$ \\
\hline EEHD & 2-Hexyldecanoic & $132 \pm 0.08$ & $>300$ & $-44 \pm 0.04$ & $84.5 \pm 0.03$ \\
\hline
\end{tabular}

to become asymmetric thus reduces the pour point tremendously and increases the viscosity value. The asymmetric condition is due to the space between these branched molecules. Branched molecules cannot be arranged very neatly because of its jagged structure. Thus it creates spaces in each molecule. This condition will lower the freezing temperature of the estolide ester because more energy is used to freeze it [13]. Longer saturated branched-chain has a bigger molecule weight which makes it is easier to lose intramolecule force, leading the solution to have a small viscosity value. The value of viscosity reduces as the length and quantity of branched fatty acid increase [14].

\section{Conclusion}

Estolide ethyl esters from ricinoleic acid and saturated fatty acid have excellent low-temperature properties and high flash points. These estolide esters have good physiochemical properties as base oil of estolide.

\section{Acknowledgments}

The authors thank UKM and the Ministry of Science and Technology for research Grants UKM-GUP-NBT-08-27-113 and UKM-OUP-NBT-29-150/2011.

\section{References}

[1] J. W. Goodrum and D. P. Geller, "Influence of fatty acid methyl esters from hydroxylated vegetable oils on diesel fuel lubricity," Bioresource Technology, vol. 96, no. 7, pp. 851-855, 2005.

[2] D. Goswami, R. Sen, J. K. Basu, and S. De, "Maximization of bioconversion of castor oil into ricinoleic acid by response surface methodology," Bioresource Technology, vol. 100, no. 18, pp. 4067-4073, 2009.

[3] M. S. Puthli, V. K. Rathod, and A. B. Pandit, "Enzymatic hydrolysis of castor oil: process intensification studies," Biochemical Engineering Journal, vol. 31, no. 1, pp. 31-41, 2006.

[4] B. H. Zoleski and F. J. Gaetani, Low Foaming Railroad Diesel Engine Lubricating Oil Composition. US Patent 4,428,850, 1984.

[5] S. C. Cermak and T. A. Isbell, "Synthesis and physical properties of cuphea oleic estolides," in Proceedings of the The Association for the Advancement of Industrial Crops Meeting, p. 34, Atlanta, Ga, USA, November 2001.

[6] B. M. Abdullah and J. Salimon, "Physicochemical characteristics of Malaysian rubber (Hevea Brasiliensis) seed oil," European Journal of Scientific Research, vol. 31, no. 3, pp. 437-445, 2009.
[7] ASTM D445-04 $€_{2}$. Standard Ttest Method for Kinematic Viscosity of Transparent and Opaque Liquids. An American Standard, 2005.

[8] ASTM Standard D 97-05a. Standard test method for Pour Point of Petroleum Products. An American Standard, 2005.

[9] ASTM D92-05a. Standard Test Method for Flash and Fire Points by Cleveland Open Cup Tester. An American Standard, 2005.

[10] T. A. Isbell and R. Kleiman, "Mineral acid-catalyzed condensation of meadowfoam fatty acids into estolides," Journal of the American Oil Chemists' Society, vol. 73, no. 9, pp. 1097-1107, 1996.

[11] S. M. Erhan, R. Kleiman, and T. P. Abbott, "Quantitation of estolides by Fourier transform infrared spectroscopy," Journal of the American Oil Chemists' Society, vol. 73, no. 5, pp. 563$567,1996$.

[12] T. A. Isbell, M. R. Edgcomb, and B. A. Lowery, "Physical properties of estolides and their ester derivatives," Industrial Crops and Products, vol. 13, no. 1, pp. 11-20, 2001.

[13] V. Štěpina and V. Veselý, Lubricants and Special Fluids, Elsevier, New York, NY, USA, 1992.

[14] C. C. Akoh, "Oxidative stability of fat substitutes and vegetable oils by the oxidative stability index method," Journal of the American Oil Chemists' Society, vol. 71, no. 2, pp. 211-216, 1994. 


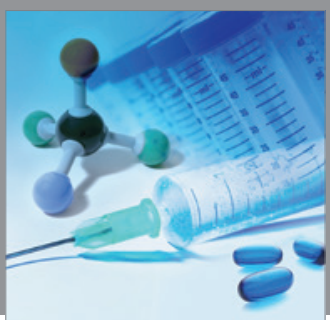

International Journal of

Medicinal Chemistry

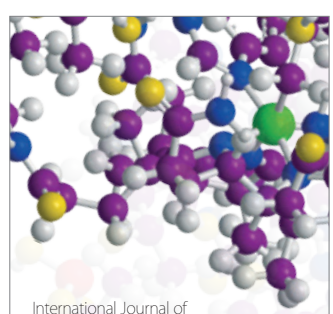

Carbohydrate Chemistry

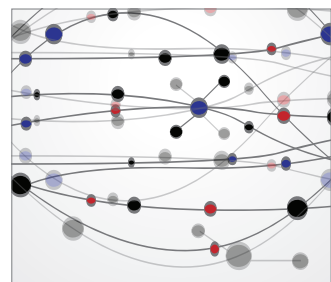

The Scientific World Journal
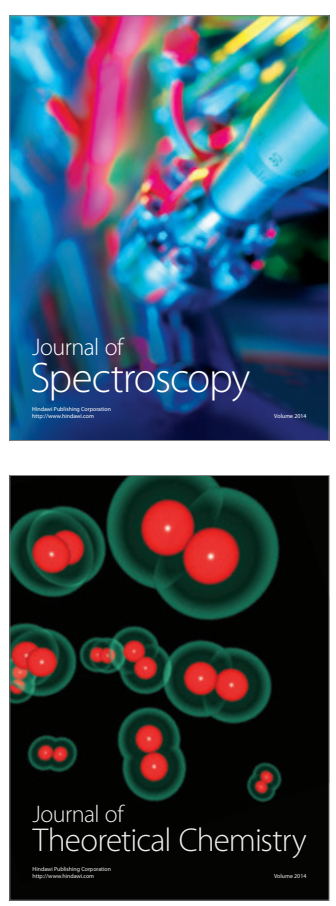
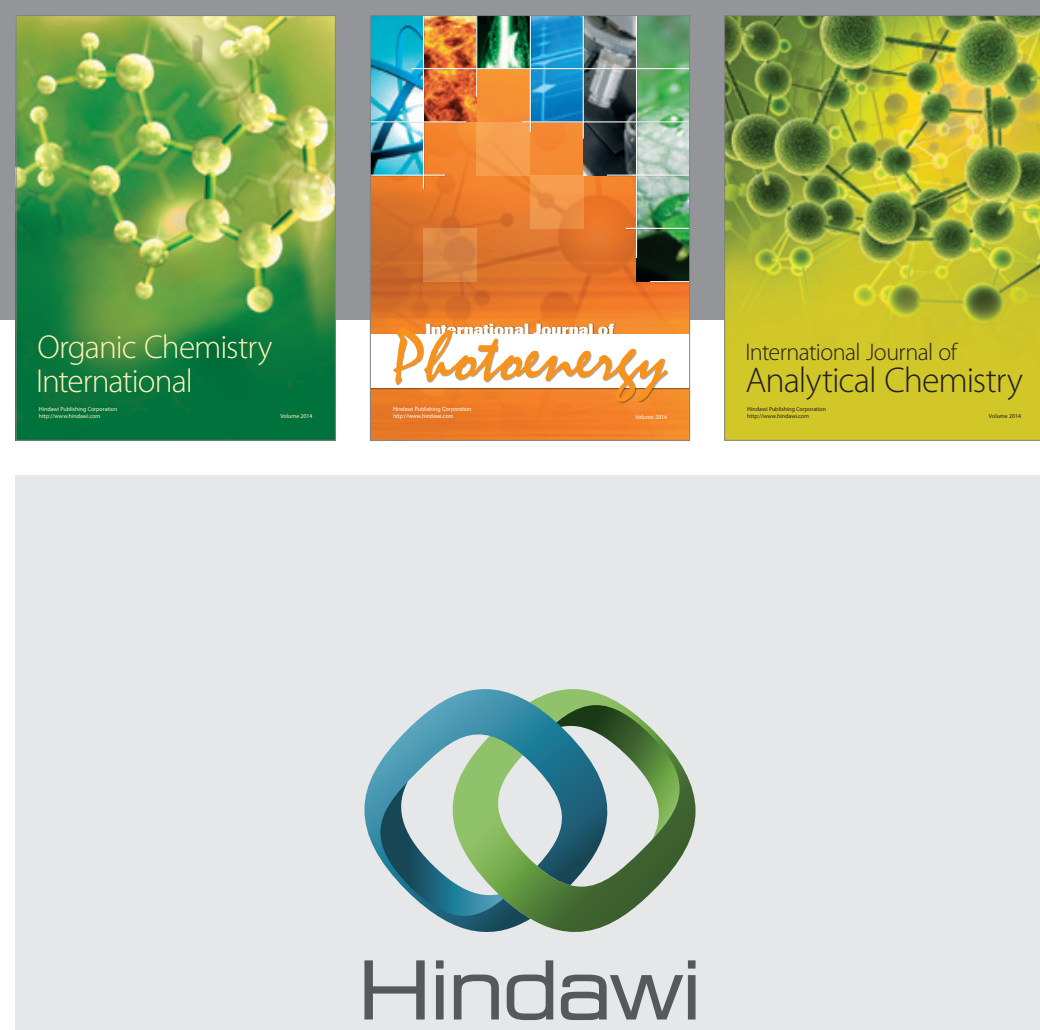

Submit your manuscripts at

http://www.hindawi.com
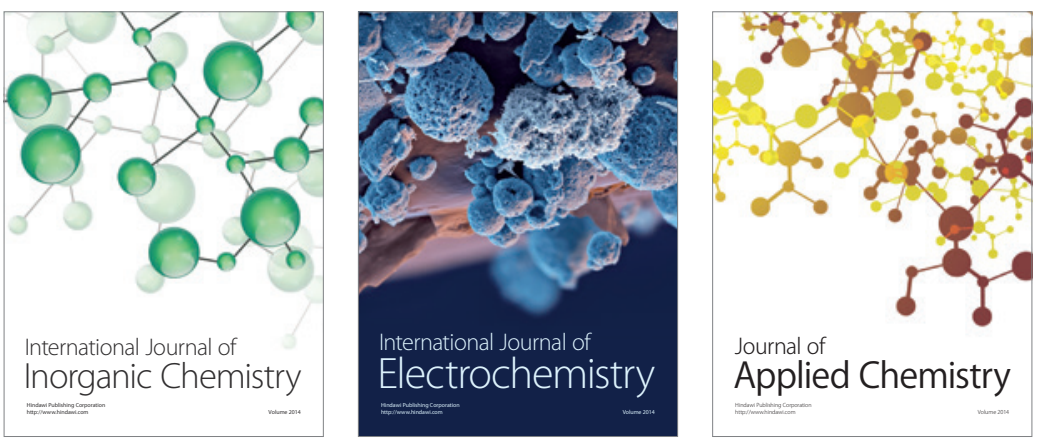

Journal of

Applied Chemistry
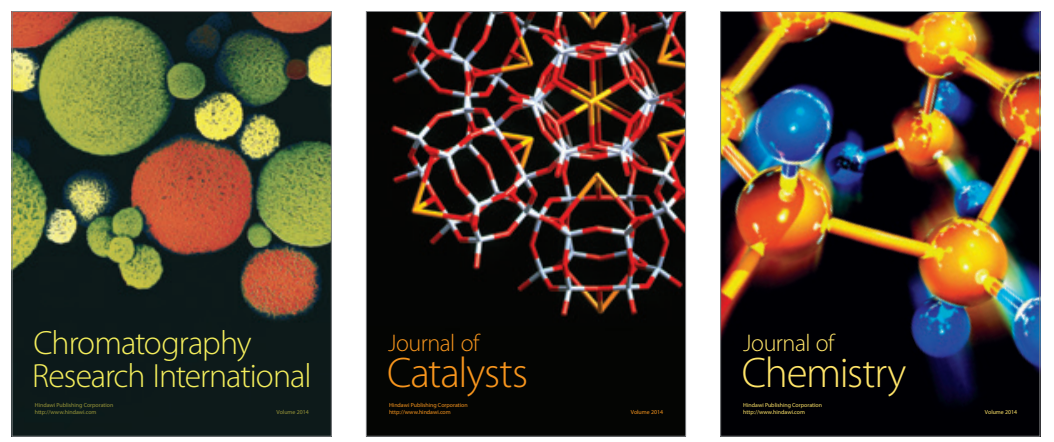
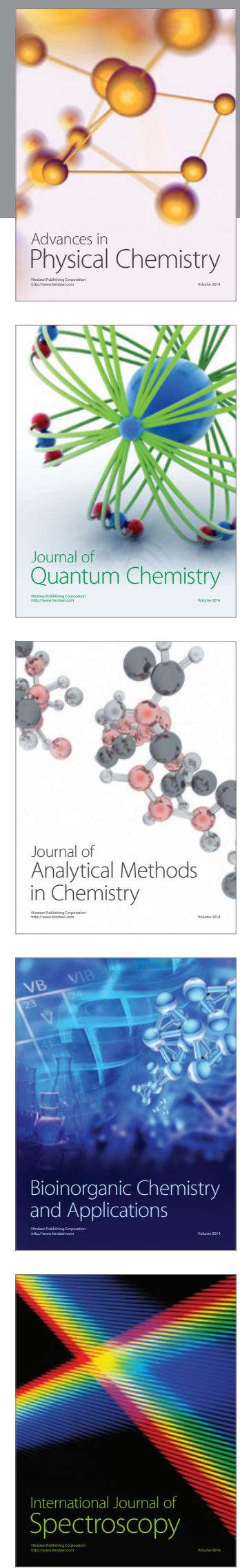